\title{
¿De quién es la ciudad histórica? Reflexiones de Heidelberg a Sevilla
}

Jaime Jover Báez | Dpto. Geografía Humana, Universidad de Sevilla

URL de la contribución <www.iaph.es/revistaph/index.php/revistaph/article/view/3585>

Compararse con Alemania se ha convertido en un cliché. Compararse y, generalmente, salir perdiendo, pues atendiendo a indicadores económicos, laborales, sociales, etc., la locomotora de la UE suele ser la referencia. Si bien no conviene dejarse llevar por estadísticas, es cierto que determinadas experiencias que allí suceden merecen la pena ser compartidas. Esta reflexión va en paralelo a dos conflictos coetáneos derivados de introducir nuevos elementos arquitectónicos en lugares singulares en las ciudades históricas de Sevilla y Heidelberg. Por qué emergen y cómo se han gestionado esos conflictos son cuestiones fundamentales para estudiar los espacios donde pasado y presente se encuentran y relacionan con mayor intensidad.

El presente, la actualidad, se llama globalización. Vivimos en un mundo de urbanización planetaria (MERRIFIELD, 2014), en el que con frecuencia se olvida que la construcción del espacio -como, en otro estadio, la del patrimonio cultural- es dialéctica. Es decir, que es tanto material como inmaterial en un proceso de autodeterminación y multiplicación. Así, el espacio se produce en el marco de un modo de producción (político-económico y sociocultural) dominante en cada tiempo, que simultáneamente es esencial en la reproducción de ese proceso productivo (LEFEBVRE, 2013). No son relaciones unidireccionales, sino que suceden en varias dimensiones, lugares y escalas al mismo tiempo.

Las ciudades históricas de la Europa occidental en los últimos cinco siglos son, por ello, producto de diversas capas de memoria colectiva tangible e intangible que se superponen, creadas en el marco de la economía capitalista en sus distintas etapas y concentradas en espacios urbanos que se han ido adaptando a los intereses de esas economías. En esta evolución, un punto de inflexión lo marca la transición de la sociedad fordista a la posfordista, de la economía de producción a la de consumo, en la creciente ola globalizadora que a partir de la década de 1970 inaugura el proceso de neoliberalización (BRENNER; THEODORE, 2002). Dentro del mismo se entiende la progresiva mercantilización de las áreas urbanas históricas hasta convertirlas en ventaja competitiva.

Como Harvey $(2001,2012)$ ha señalado, para la gran mayoría de las ciudades del mundo, el dinamismo económico pasa por la atracción de capitales, inversores y turistas, siguiéndose una estrategia empresarial: se busca la generación de plusvalías a través de la diferenciación constante del producto, la ciudad y su marca urbana, resaltándose la calidad de determinados espacios, que se muestran como únicos y se transforman en mercancía-lugar. Tales estrategias han sido impuestas mediante la gobernanza del empresarialismo urbano, lo que supone maximizar el beneficio privado en espacios patrimoniales, cuyo destino -como conjunto urbano histórico- es público, mediante un marco de regulación diseñado al efecto.

La contradicción emerge cuando tales estrategias conllevan procesos de gentrificación, banalización de paisajes, homogeneización de espacios públicos y pérdida de identidad en las ciudades históricas (ver NEF, 2004; DÍAZ PARRA, 2014). El problema es obvio si entendemos que una ciudad es un organismo complejo, vivo, y no un simple bien de consumo. Como he argumentado para el caso de Sevilla (JOVER BÁEZ, 2014), la autenticidad de la ciudad histórica como conjunto urbano no reside exclusivamente en su patrimonio material, sino especialmente en aquellos valores que le aportan quienes la hacen día a día: los ciudadanos. Comprender que la ciudad pertenece a aquellos que la habitan es la principal diferencia entre Sevilla y Heidelberg. Con la 


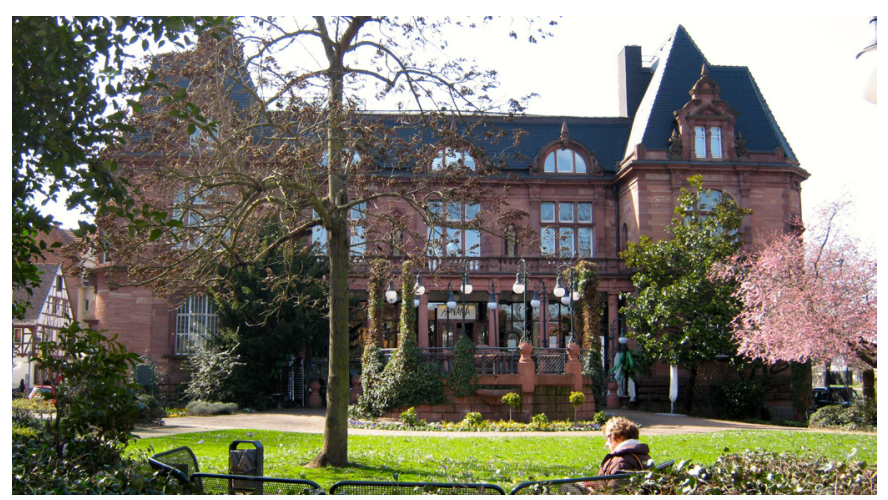

Stadthalle y la plaza que iba a desaparecer con el nuevo proyecto en la ciudad alemana de Heidelberg, marzo 2011 | foto Jaime Jover Báez

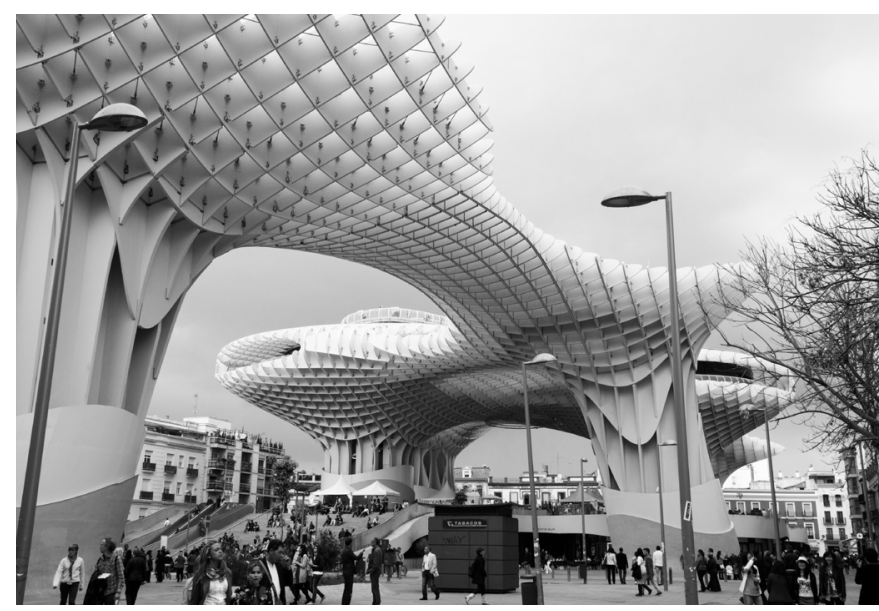

Proyecto Metropol Parasol en la plaza de la Encarnación en Sevilla | foto Jesús León (https://www.flickr.com/photos/jesusleon)

excusa de "poner la ciudad en el mapa", las estrategias en Sevilla en la primera década del s. XXI han llevado a la construcción de, entre otros, el Metropol Parasol en pleno corazón del conjunto histórico. Aquí, la cuestión estética se ha situado frecuentemente en el centro del debate, marginando otras como su conveniencia arqueológica, coyuntural, escalar y, por encima de todo, su legitimación social.

Al mismo tiempo que se levantaban "Las setas" en la plaza de la Encarnación, en Heidelberg, al sudoeste de Alemania, ocurría una experiencia opuesta y ejemplar. Heidelberg, en el Estado federado de Baden-
Württemberg, es una ciudad de poco más de 150.000 habitantes, que ejerce de capital cultural de la región metropolitana Rhein-Neckar, en la que viven casi 2,5 millones de personas. A orillas del río Neckar, es sede de la universidad más antigua de Alemania y una de las más antiguas de Europa. Precisamente paralelo a este río se sitúa el centenario palacio de congresos o Stadthalle, que el Ayuntamiento buscaba ampliar para atraer más actividades, seminarios y conferencias (en definitiva, inversiones) a la ciudad. El edificio que se planteaba, anexo al actual y también paralelo al río, ocupaba el espacio de una plaza ajardinada y rompía el esquema histórico -tejido y paisaje- urbano ${ }^{1}$. Tal proyecto encontró la oposición de un grupo de ciudadanos que, ante la posibilidad que les otorga la legislación de hacer una consulta, recogieron hasta 18.000 firmas a tal efecto. El referéndum se celebró en julio de 2010 con una participación del 38,9\% del electorado, superando el quórum establecido, de los que el 67,1\% (26.324 personas) votaron en contra del proyecto, provocando que el Ayuntamiento decidiera suspender la ejecución del mismo (STADT HEIDELBERG, 2010).

El caso de Heidelberg ilustra el conflicto sobre quién y cómo se decide sobre la producción de nuevos espacios en la ciudad histórica global. Generar nuevos símbolos mediante arquitectura contemporánea en tramas urbanas históricas suele responder a la lógica mercantilista de producción y reproducción del capitalismo transnacional, frecuentemente en tensión con el carácter democrático y plural del patrimonio histórico. Si éste, tal como lo entendemos hoy, lo protegemos debido a su capacidad de totalizar nuestro pasado y significar una identidad colectiva, parece comprensible que, ante alteraciones sustanciales que incumben a todos como la de un paisaje urbano histórico, sean todos los ciudadanos los que tengan derecho a expresarse. Experiencias de las que administraciones y sociedad civil sevillana y andaluza deberíamos aprender. 


\section{NOTA}

1. Detalles del proyecto pueden encontrarse en el siguiente enlace: $<$ http://divisare.com/projects/120457-Stadthalle-Heidelberg> [Consulta: $26 / 01 / 2015]$

\section{BIBLIOGRAFÍA}

- BRENNER, N.; THEODORE, N. (2002) Cities and the Geographies of "Actually Existing Neoliberalism". Antipode, 34 (3), 2002, pp. 349-378

- DÍAZ PARRA, I. (2014) ¿Gentrificación o barbarie? Disciplinamiento y transformación social del barrio de la Alameda de Sevilla. Sevilla: Atrapasueños, 2014

- HARVEY, D. (2001) Spaces of capital. Edimburgo: Edinburgh University Press, 2001

- HARVEY, D. (2012) Rebel Cities. Londres: Verso, 2012

- JOVER BÁEZ, J. (2014) La ciudad histórica neoliberal. Experiencias de resistencia al neoliberalismo en el centro de Sevilla. En Actas del Encuentro de Jóvenes Investigadores en Geografía. Universidad de Barcelona, 28-30 de mayo 2014, pp. 147-154

- LefebVRE, H. (2013) La producción del espacio. 1. ${ }^{\mathrm{a}}$ edición 1974. Madrid: Capitán Swing, 2013

- MERRIFIELD, A. (2014) The new urban question. Londres: Pluto Press, 2014

- NEF. NEW ECONOMICS FOUNDATION (2004) Clown Towns Britain. Londres: NEF, 2004

- STADT HEIDELBERG (2010) Ergebnisse und Kurzanalyse des Bürgerentscheides zur Stadthallen erweiterung am 25. Juli 2010. Heidelberg: Stadt Amt für Stadtentwicklung und Statistik, 2010 